\title{
Improved survival after coronary artery bypass grafting has not influenced the mortality disadvantage in patients with diabetes mellitus
}

\author{
Thomas Alserius, MD, PhD, ${ }^{\mathrm{a}, \mathrm{c}}$ Niklas Hammar, $\mathrm{PhD},{ }^{\mathrm{d}}$ Tobias Nordqvist, $\mathrm{MSc},{ }^{\mathrm{b}}$ and \\ Torbjörn Ivert, MD, $\mathrm{PhD}^{\mathrm{a}, \mathrm{c}}$
}

Objectives: We sought to compare mortality after coronary artery bypass grafting in patients with and without diabetes mellitus undergoing operations during different time periods.

Methods: We performed analyses of 12,415 primary isolated coronary artery bypass grafting operations performed during 1970-2003, with follow-up of 5-year mortality up to December 2006.

\begin{abstract}
Results: The prevalence of diabetes mellitus continuously increased up to $25 \%$ among patients undergoing coronary artery bypass grafting in 2003 . The 1892 patients with type 2 diabetes mellitus were older, more often female, and more frequently had cardiovascular risk factors, acute coronary syndrome, 3-vessel disease, and severely reduced left ventricular function than patients without diabetes mellitus. Early mortality was $3.4 \%$ in patients with diabetes mellitus versus $1.8 \%$ in patients without diabetes mellitus. The multivariable adjusted odds ratio was 2.0 , and the $95 \%$ confidence interval was 1.4 to 2.7 . Early adjusted mortality was significantly lower in patients operated on during 2000-2003 than those operated on during 1970-1989 in patients with diabetes mellitus (odds ratio, $0.3 ; 95 \%$ confidence interval, $0.1-0.9$ ) and without diabetes mellitus (odds ratio, 0.4; $95 \%$ confidence interval, $0.2-0.7$ ). Mortality until 5 years was $14.6 \%$ in patients with diabetes mellitus versus $8.3 \%$ in patients without diabetes mellitus (hazard ratio, $1.8 ; 95 \%$ confidence interval, $1.5-2.0$ ). Five-year mortality was reduced by $40 \%$ in patients operated on during 2000-2003 compared with that seen in those operated on during 1970-1989 in patients with and without diabetes mellitus.
\end{abstract}

Conclusions: Diabetes mellitus was associated with an almost 2-fold increased risk of early and 5-year mortality. Early and late mortality were substantially reduced in patients with and without diabetes mellitus operated on more recently, but the mortality disadvantage associated with diabetes mellitus was not eliminated.

Patients with diabetes mellitus (DM) have a generalized vascular disease and often extensive coronary artery disease with diffuse peripheral obstructive lesions. ${ }^{1-4}$ Many studies have documented higher early mortality after coronary artery bypass grafting $(\mathrm{CABG})$ in patients with $\mathrm{DM}$ than in those without DM. ${ }^{1,5-9}$ In other reports early mortality did not differ. ${ }^{10-14} \mathrm{DM}$ is in most reports recognized as an independent predictor of 5-year mortality after CABG. ${ }^{8,10,11,15-18}$ Conversely, Calafiore and colleagues, ${ }^{6}$ who used multiple arterial grafts, did not find that DM, exclusive of patients with diet treatment, was associated with a worse 5-year mor-

\footnotetext{
From the Department of Cardiothoracic Surgery and Anaesthesiology, ${ }^{\text {a }}$ Karolinska University Hospital; the Department of Epidemiology, ${ }^{\mathrm{b}}$ Stockholm Center of Public Health; and the Department of Molecular Medicine and Surgery ${ }^{\mathrm{c}}$ and Epidemiology, ${ }^{\mathrm{d}}$ Institute of Environmental Medicine, Karolinska Institute, Stockholm, Sweden.

Supported by the Tornspiran and the Mats Klebergs Foundations and EXPO 95 of the Stockholm County Council.

Received for publication Nov 19, 2008; revisions received Feb 13, 2009; accepted for publication March 8, 2009.

Address for reprints: Torbjörn Ivert, MD, PhD, Department of Cardiothoracic Surgery and Anaesthesiology, Karolinska University Hospital, S-171 76 Stockholm, Sweden (E-mail: torbjorn.ivert@karolinska.se).

J Thorac Cardiovasc Surg 2009;138:1115-22

$0022-5223 / \$ 36.00$

Copyright (c) 2009 by The American Association for Thoracic Surgery

doi:10.1016/j.jtcvs.2009.03.013
}

tality. There is agreement that the prognosis is worse in patients with insulin-treated DM than in those taking oral hypoglycemic medication. ${ }^{1,8,13,14,16,17}$ During recent years, there has been substantial attention to risk factor reduction in patients with cardiovascular disease and improvements in the management of patients with DM that might have reduced the mortality disadvantage associated with DM.

The purpose of our study was to analyze mortality up to 5 years after a first isolated $\mathrm{CABG}$ operation performed during more than 3 decades in patients with and without type $2 \mathrm{DM}$ to examine whether mortality differed in the 2 groups and whether any difference was influenced by changes in survival prognosis related to the time period of the operation.

\section{MATERIALS AND METHODS Patients}

From June 1970, when the first CABG operation was performed in Sweden, through December 2003, a total of 12,557 patients had a first-time isolated CABG operation at the Karolinska University Hospital in Stockholm. Demographic variables and clinical characteristics that are continuously recorded in the department database were validated. This information, as well as information extracted by means of review of medical records, was used for the present study. In patients with DM, the year of diagnosis, as well as the type and dose of medication, was recorded. In total, $2034(16 \%)$ patients had DM, 142 of whom (7\%) had type 1 DM. The latter patient group 


$$
\begin{aligned}
& \text { Abbreviations and Acronyms } \\
& \begin{aligned}
\text { ACE } & =\text { angiotensin-converting enzyme } \\
\text { BMI } & =\text { body mass index } \\
\text { CABG } & =\text { coronary artery bypass grafting } \\
\text { CI } & =\text { confidence interval } \\
\text { DM } & =\text { diabetes mellitus } \\
\text { HR } & =\text { hazard ratio } \\
\text { OR } & =\text { odds ratio } \\
\text { PCI } & =\text { percutaneous coronary intervention }
\end{aligned}
\end{aligned}
$$

was small, with an average age 11 years less than that of patients with type 2 DM. Our analyses were confined to the 1892 patients with type 2 DM and the 10,523 patients without a diagnosis of DM. Throughout the long time period, major improvements were introduced regarding operative technique, myocardial protection, perioperative management, and pharmacologic treatment of diabetes and cardiovascular risk factors. From 1983, all patients routinely received lifelong treatment with $160 \mathrm{mg}$ of acetylsalicylic acid daily from the first postoperative day after CABG. Use of angiotensinconverting enzyme (ACE) inhibitors increased from 22\% during 19961999 to $35 \%$ during 2000-2003, and the corresponding use of statins increased from $49 \%$ to $71 \%$. The study was approved by the local ethics committee in Stockholm.

\section{Definitions}

DM included patients admitted with a clinical diagnosis of DM who were treated with insulin, oral medication, or both or had a diet regimen only. In this report patients having a transient perioperative increase in blood glucose levels were not classified as having DM. Type 2 DM was usually initially not insulin dependent and frequently associated with insulin resistance.

Body mass index (BMI) was calculated by dividing weight in kilograms by the square of height in meters. Serum creatinine values were measured at the time of hospital admission. Creatinine clearance was calculated by using the equation of Cockroft and Gault. ${ }^{19}$ Normal renal function was defined as a creatinine clearance of $80 \mathrm{~mL} / \mathrm{min}$ or greater.

Acute coronary syndrome was defined as chest pain at rest on admittance to the hospital or new onset or accelerated angina within 4 weeks of the operation. Peripheral vascular disease was defined as a history of exertional claudication, prior revascularization to the legs, or both. Normal left ventricular function was defined as an ejection fraction of greater than $50 \%$ without dilatation of the ventricle. Reduced left ventricular function was defined as an ejection fraction of less than $50 \%$ but greater than $30 \%$. Severely reduced left ventricular function was defined as a markedly dilated ventricle with akinetic or hypokinetic segments and an estimated ejection fraction of less than $30 \%$.

\section{Follow-up}

Follow-up of mortality was performed by linking each subject's Swedish personal identification number to the National Cause of Death Register 1970-2002 and to the National Population Register for deaths occurring between 2003 and December 2006. Early mortality was defined as death occurring within 30 days of surgical intervention. All patients were followed at least 3 years with regard to vital status.

\section{Statistical Methods}

Early mortality was compared in patients with and without DM and multivariably adjusted by using odds ratios (ORs) from logistic regression analyses. Crude and adjusted hazard ratios (HRs) of deaths within 5 years after CABG were estimated by using Cox's proportional hazard regres- sion. Mortality was analyzed separately for early deaths and for deaths occurring from 30 days until 5 years after the operation among survivors at 30 days. All variables listed in Table 1 were considered for inclusion in the multivariable models. In the final analyses adjustment was made for confounding factors by using a change-in-point estimate approach. Variables that changed the OR or HR by at least 0.1 when adjusted for in the multivariable analyses were included in the final model. Estimates of ORs and HRs were accompanied by asymptotic $95 \%$ confidence intervals (CIs). In the multivariable analyses age, BMI, and creatinine clearance were included in the models as continuous variables, and other variables were included as dichotomous variables, representing the presence or absence of the characteristic. Year of surgical intervention was divided into the 3 time periods of 1970-1989, 1990-1999, and 2000-2003 because there were few patents with DM during the initial 2 decades. Left ventricular function was categorized as normal, reduced, or severely reduced. Continuous variables are presented as the mean with 1 standard deviation. The Student's $t$ test was used to compare differences in means between patient groups. The logarithm of values was used in case of skewed distributions. The $\chi^{2}$ test or the 2-tailed Fisher's exact test was used to compare categorical data. Kaplan-Meier estimates of survival up to 5 years after surgical intervention were calculated.

\section{RESULTS}

During the 34 years from 1970 through 2003, patients having type $2 \mathrm{DM}$ undergoing CABG accounted for an increasing proportion that was $25 \%$ in 2003 (Figure 1). The initial 19 years up to 1989 included only $17 \%$ of the 1892 patients with type $2 \mathrm{DM}$. Throughout the 3 time periods of 1970-1989, 1990-1999, and 2000-2003, average age increased, and cardiovascular risk factors, acute coronary syndrome, 3-vessel disease, and left main stem stenosis became increasingly more common in patients with and without DM (Table 1). BMI, creatinine clearance, history of previous myocardial infarction, and peripheral vascular disease remained essentially unchanged. An increasing proportion of patients with DM had insulin treatment or oral medication. Among 722 patients with insulin treatment, $202(27 \%)$ also received oral hypoglycemic medication. Year of diagnosis of DM until year of CABG was significantly greater $(P<.01)$ in patients operated on during 1990-1999 (15.6 \pm 16.0 years) than during 2000-2003 (9.5 \pm 8.9 years). Single-vessel disease became less common. During $2000-2003$, almost $80 \%$ of the patients received 3 to 4 or more distal coronary anastomoses. An internal thoracic artery graft was inserted in $95 \%$ of patients from 1990, regardless of DM diagnosis.

Patients with DM were characterized by older age, higher BMI and creatinine clearance values, higher preponderance of female sex, hypertension, hyperlipidemia, acute coronary syndrome, previous myocardial infarction and stroke, peripheral vascular disease, 3-vessel disease, and severely reduced left ventricular function than those without DM. The number of coronary anastomoses did not differ in patients with and without DM.

Overall survival until 5 years was less in patients with DM than in those without DM (Figure 2). Survival was lowest in patients with DM undergoing CABG during 1970-1989, 
TABLE 1. Characteristics of 12,415 patients undergoing coronary artery bypass grafting during 1970-2003 in relation to time period of the operation and diagnosis of type 2 diabetes mellitus

\begin{tabular}{|c|c|c|c|c|c|c|c|c|}
\hline & \multicolumn{3}{|c|}{ No diabetes, $n=10,523(85 \%)$} & \multicolumn{4}{|c|}{ Type 2 diabetes, $n=1892(15 \%)$} & \multirow[b]{2}{*}{$P$ value } \\
\hline & $\begin{array}{c}1970-1989 \\
\mathbf{n}=3488(33 \%) \\
\text { mean } \pm \text { SD }\end{array}$ & $\begin{array}{c}1990-1999 \\
\mathbf{n}=\mathbf{5 1 6 6}(49 \%), \\
\text { mean } \pm \text { SD }\end{array}$ & $\begin{array}{c}2000-2003, \\
\mathbf{n}=1869(18 \%) \\
\text { mean } \pm \text { SD }\end{array}$ & $P$ value* & $\begin{array}{c}1970-1989 \\
\mathbf{n}=319(17 \%) \\
\text { mean } \pm \text { SD }\end{array}$ & $\begin{array}{c}1990-1999 \\
\mathbf{n}=989(52 \%) \\
\text { mean } \pm \text { SD }\end{array}$ & $\begin{array}{c}2000-2003 \\
\mathbf{n}=\mathbf{5 8 4}(31 \%), \\
\text { mean } \pm \text { SD }\end{array}$ & \\
\hline Age (y) & $58 \pm 8$ & $65 \pm 10$ & $66 \pm 10$ & $<.01$ & $59 \pm 8$ & $65 \pm 9$ & $67 \pm 9$ & $<.01 \dagger$ \\
\hline BMI $\left(\mathrm{kg} / \mathrm{m}^{2}\right)$ & $26 \pm 3$ & $26 \pm 4$ & $26 \pm 4$ & .84 & $28 \pm 4$ & $28 \pm 4$ & $28 \pm 4$ & $.81 \dagger$ \\
\hline $\begin{array}{l}\text { Creatinine } \\
\text { clearance (mL/ } \\
\text { min) }\end{array}$ & $82 \pm 23$ & $79 \pm 27$ & $82 \pm 27$ & .02 & $84 \pm 27$ & $85 \pm 30$ & $86 \pm 32$ & $.59 \dagger$ \\
\hline Female sex & $14 \%$ & $20 \%$ & $21 \%$ & $<.01$ & $20 \%$ & $26 \%$ & $25 \%$ & $.25 \dagger$ \\
\hline Hypertension & $24 \%$ & $31 \%$ & $63 \%$ & $<.01$ & $52 \%$ & $46 \%$ & $75 \%$ & $<.01 \dagger$ \\
\hline \multicolumn{9}{|l|}{ Diabetes } \\
\hline Insulin & - & - & - & - & $25 \%$ & $40 \%$ & $52 \%$ & $<.01 \dagger$ \\
\hline Oral drugs & - & - & - & - & $51 \%$ & $54 \%$ & $65 \%$ & $<.01 \dagger$ \\
\hline Diet treated & - & - & - & - & $25 \%$ & $14 \%$ & $11 \%$ & $<.01 \dagger$ \\
\hline Hyperlipidemia & $7 \%$ & $34 \%$ & $73 \%$ & $<.01$ & $13 \%$ & $36 \%$ & $75 \%$ & $<.01 \dagger$ \\
\hline Previous AMI & $52 \%$ & $51 \%$ & $51 \%$ & .07 & $63 \%$ & $54 \%$ & $59 \%$ & $.26 \dagger$ \\
\hline $\begin{array}{l}\text { Acute coronary } \\
\text { syndrome }\end{array}$ & $6 \%$ & $27 \%$ & $40 \%$ & $<.01$ & $4 \%$ & $29 \%$ & $40 \%$ & $<.01 \dagger$ \\
\hline History of stroke & $3 \%$ & $7 \%$ & $7 \%$ & $<.01$ & $4 \%$ & $9 \%$ & $12 \%$ & $<.01 \dagger$ \\
\hline $\begin{array}{l}\text { Peripheral vascular } \\
\text { disease }\end{array}$ & $6 \%$ & $6 \%$ & $6 \%$ & .39 & $11 \%$ & $11 \%$ & $10 \%$ & $.83 \dagger$ \\
\hline \multicolumn{9}{|l|}{ Coronary disease } \\
\hline Single vessel & $15 \%$ & $7 \%$ & $6 \%$ & $<.01$ & $8 \%$ & $3 \%$ & $4 \%$ & $<.01 \dagger$ \\
\hline Two vessel & $33 \%$ & $22 \%$ & $20 \%$ & & $29 \%$ & $17 \%$ & $15 \%$ & \\
\hline Three vessel & $50 \%$ & $70 \%$ & $73 \%$ & & $62 \%$ & $80 \%$ & $81 \%$ & \\
\hline Missing & $2 \%$ & $1 \%$ & $0 \%$ & & $2 \%$ & $0 \%$ & $0 \%$ & \\
\hline Left main stem & $13 \%$ & $21 \%$ & $26 \%$ & $<.01$ & $14 \%$ & $19 \%$ & $22 \%$ & $<.01$ \\
\hline \multicolumn{9}{|l|}{ LV function } \\
\hline Normal & $59 \%$ & $55 \%$ & $64 \%$ & .43 & $54 \%$ & $49 \%$ & $52 \%$ & $.39 \dagger$ \\
\hline Reduced & $35 \%$ & $33 \%$ & $26 \%$ & & $37 \%$ & $37 \%$ & $33 \%$ & \\
\hline Severely reduced & $4 \%$ & $7 \%$ & $6 \%$ & & $7 \%$ & $9 \%$ & $11 \%$ & \\
\hline No information & $2 \%$ & $6 \%$ & $5 \%$ & & $3 \%$ & $5 \%$ & $4 \%$ & \\
\hline \multicolumn{9}{|l|}{ No. of anastomoses } \\
\hline $1-2$ & $39 \%$ & $16 \%$ & $24 \%$ & $<.01$ & $27 \%$ & $11 \%$ & $23 \%$ & $.01 \dagger$ \\
\hline $3-4$ & $51 \%$ & $70 \%$ & $69 \%$ & & $58 \%$ & $72 \%$ & $70 \%$ & \\
\hline $5-8$ & $11 \%$ & $15 \%$ & $8 \%$ & & $15 \%$ & $17 \%$ & $8 \%$ & \\
\hline Use of ITA & $73 \%$ & $95 \%$ & $95 \%$ & $<.01$ & $81 \%$ & $95 \%$ & $95 \%$ & $<.01 \dagger$ \\
\hline
\end{tabular}

$S D$, Standard deviation; $B M I$, body mass index; $A M I$, acute myocardial infarction; $L V$, left ventricular, $I T A$, internal thoracic artery. $* P$ value for trend. Age, body mass index, and creatinine clearance are calculated with the crude model in regression analysis. Other $P$ values are calculated by using the Mantel-Haenszel $\chi^{2}$ test. $\dagger P<.001$ for global difference between patients with versus those without diabetes.

despite the fact that they were, on average, 8 years younger than patients operated on during 2000-2003. Unadjusted survival at 5 years was $89.5 \%, 89.9 \%$, and $90.6 \%$ in patients without DM operated on during 1970-1989, 1990-1999, and 2000-2003, respectively. The corresponding figures for patients with DM were $78.1 \%, 83.2 \%$, and $81.7 \%$.

Early mortality during 1970-2003 after a first isolated CABG operation was $3.4 \%$ in patients with DM versus $1.8 \%$ in patients without DM, yielding a 2 -fold higher risk in patients with DM after multivariable correction for age and other confounders (Table 2). There was no clear trend over time periods in the ORs for early mortality in patients with versus those without DM, but during the latest time period (2000-2003), the OR was somewhat lower, with a 95\% CI including 1.0 (OR, 1.5; 95\% CI, 0.8-2.9). Similarly, late mortality among survivors at 30 days until 5 years after the operation was almost 2 times higher after multivariable correction in patients with DM versus that seen in patients without DM (HR, 1.8; 95\% CI, 1.5-2.0). This mortality disadvantage in patients with a diagnosis of DM was essentially unchanged across the 3 time periods.

The multivariable adjusted risk of early death during 2000-2003 compared with 1970-1989 was significantly reduced both in patients with DM (OR, 0.3; 95\% CI, 0.1-0.9) and those without DM (OR, 0.4; 95\% CI, 0.2-0.7), taking changes in patient characteristics during the 3 decades into 


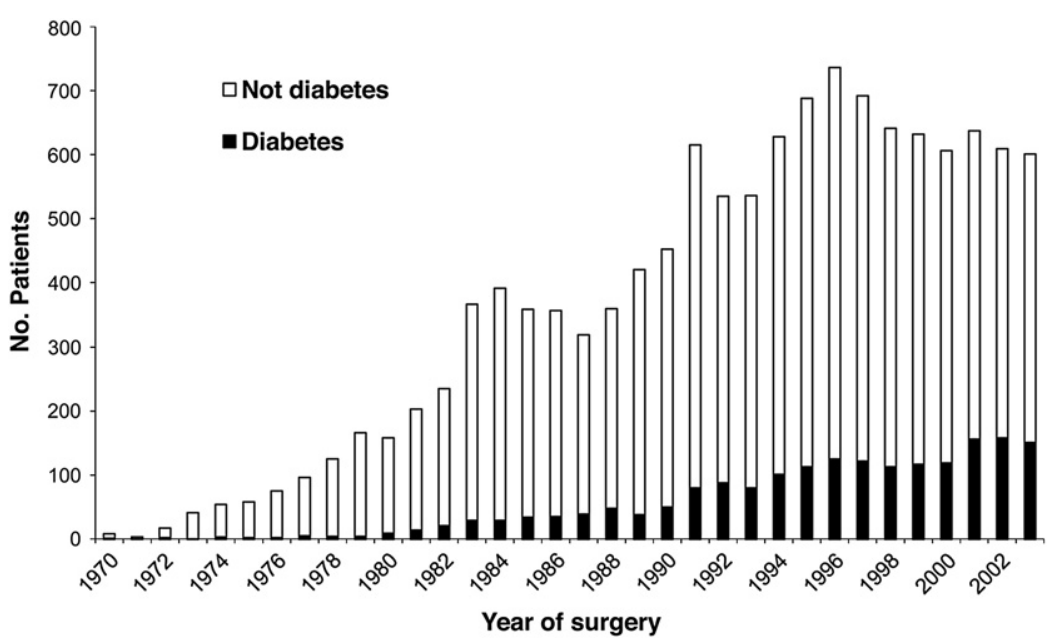

FIGURE 1. Annualized proportion of patients with type 2 diabetes mellitus among 12,415 patients undergoing isolated artery bypass grafting during 19702003.

account (Table 3). This is equivalent to a $2.1 \%$ average reduction of early mortality per year in patients with DM and $1.8 \%$ in patients without DM during the 33 years after correction for confounders. Furthermore, the multivariable corrected risk of late death was similarly reduced by $40 \%$ in patients with and in those without DM after CABG performed during 2000-2003 compared with that seen in patients operated on during 1970-1989. The reduction in late mortality per year was $2 \%(95 \% \mathrm{CI}, 0 \%-4 \%)$ in patients with DM and 3\% (95\% CI, 2\%-4\%) in those without DM.

Late mortality was significantly reduced in patients with DM and insulin treatment or oral medication during 2000 2003 compared with that seen during 1970-1989 (Table 4). Any change in mortality among the few patients who had diet management only could not be assessed, as indicated by the HRs with wide confidence limits.

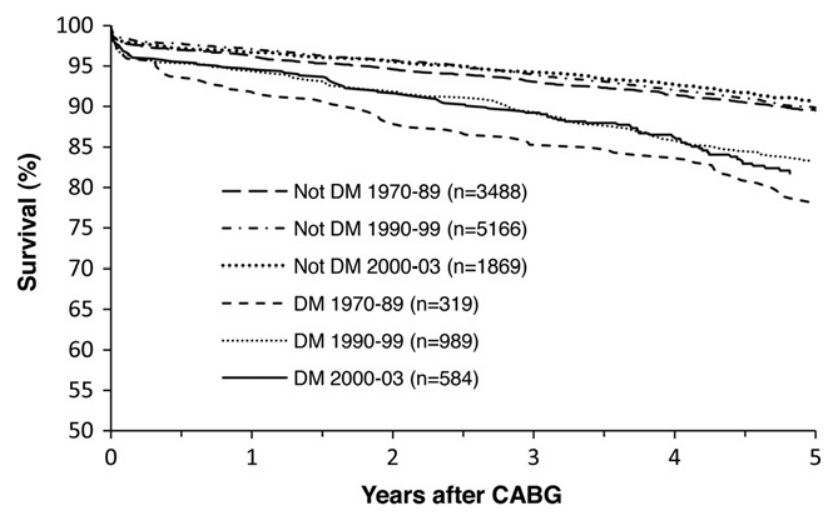

FIGURE 2. Five-year survival after coronary artery bypass grafting (CABG) performed during 1970-1989, 1990-1999, and 2000-2003, respectively, in patients with and without type 2 diabetes mellitus $(D M)$. The $y$-axis ranges from $50 \%$ survival.

\section{DISCUSSION}

Consistent with other reports, we found that patients with DM accepted for CABG were more likely to be female and more often have comorbidities, such as higher BMI, previous stroke, history of hypertension, peripheral vascular disease, unstable coronary syndrome, poorer left ventricular function, and more extensive coronary artery disease, than patients without DM. ${ }^{5,7,10,13,14,20}$ Use of an arterial graft and completeness of revascularization at the time of the operation was equally high in our patients with and without DM. Patients with type 2 DM included in our analyses frequently had concurrent cardiovascular risk factors and were usually initially not insulin dependent. Among the patients with DM, age and comorbidities increased during the 3 decades, whereas renal function and peripheral vascular disease did not change, indicating better preserved end-organ function, probably as a result of recent improved medical management and earlier diagnosis of DM because patients operated on during 2000-2003 had shorter durations of DM diagnosis than those undergoing CABG during 1990-1999. Type 2 DM with insulin resistance is closely associated with the metabolic syndrome. Echahidi and coworkers ${ }^{21}$ reported a 2.7 -fold increase in the risk of death within 30 days of CABG in patients with metabolic syndrome and DM and a 2.4-fold increased risk in patients with metabolic syndrome without DM but no increased risk in the patients with DM but not metabolic syndrome.

A variety of causes might explain a marked increase in patients with DM having CABG, as also observed by other authors. ${ }^{13}$ During the initial experience, surgeons were reluctant to accept patients for CABG with the peripherally located coronary obstructions often observed in patients with DM. Better recent recognition of a DM diagnosis might also have contributed to the increase. Randomized trials have shown that $\mathrm{CABG}$ is a better alternative than 
TABLE 2. Early and late mortality 30 days until 5 years after coronary artery bypass grafting during 3 time periods in patients with type 2 diabetes mellitus compared with that seen in patients without diabetes mellitus

\begin{tabular}{|c|c|c|c|c|c|c|c|c|c|c|}
\hline \multirow[b]{2}{*}{ Time period } & \multirow{2}{*}{$\begin{array}{l}\text { DM } \\
\text { No. }\end{array}$} & \multicolumn{2}{|c|}{ Deaths } & \multirow{2}{*}{$\begin{array}{c}\text { No DM } \\
\text { No. } \\
\end{array}$} & \multicolumn{2}{|c|}{ Deaths } & \multicolumn{2}{|c|}{ Age adjusted } & \multicolumn{2}{|c|}{ Multivariable* } \\
\hline & & $\mathbf{n}$ & $\%$ & & $\mathbf{n}$ & $\%$ & OR & $95 \%$ CI & OR & $95 \%$ CI \\
\hline \multicolumn{11}{|l|}{ Early deaths } \\
\hline 1970-2003 & 1892 & 64 & 3.4 & 10,523 & 187 & 1.8 & 1.8 & $1.4-2.4$ & 2.0 & $1.4-2.7$ \\
\hline 1970-1989 & 319 & 11 & 3.5 & 3488 & 72 & 2.1 & 1.5 & $0.8-3.0$ & 1.9 & $1.0-3.9$ \\
\hline 1990-1999 & 989 & 35 & 3.5 & 5166 & 79 & 1.5 & 2.5 & $1.6-3.8$ & 2.8 & $1.7-4.4$ \\
\hline 2000-2003 & 584 & 18 & 3.1 & 1869 & 36 & 1.9 & 1.6 & $0.9-3.0$ & 1.5 & $0.8-2.9$ \\
\hline Late deaths & & & & & & & HR & $\mathbf{9 5} \% \mathrm{CI}$ & HR & $95 \%$ CI \\
\hline 1970-2003 & 1828 & 267 & 14.6 & 10,336 & 859 & 8.3 & 1.7 & $1.5-2.0$ & 1.8 & $1.5-2.0$ \\
\hline 1970-1989 & 308 & 59 & 19.2 & 3416 & 293 & 8.6 & 2.3 & $1.7-3.0$ & 2.1 & $1.5-2.9$ \\
\hline 1990-1999 & 954 & 131 & 13.7 & 5087 & 444 & 8.7 & 1.7 & $1.4-2.0$ & 1.7 & $1.4-2.1$ \\
\hline 2000-2003 & 566 & 77 & 13.6 & 1833 & 122 & 6.7 & 2.1 & $1.6-2.9$ & 1.9 & $1.4-2.5$ \\
\hline
\end{tabular}

$D M$, Diabetes mellitus; $O R$, odds ratio; $95 \% C I, 95 \%$ confidence interval; $H R$, hazard ratio. *Adjusted for age, unstable angina pectoris, left ventricular function, creatinine clearance, history of myocardial infarction, use of an internal thoracic artery graft, length, and weight.

percutaneous coronary intervention (PCI) in patients with DM and multivessel coronary artery disease because of higher rates of complete revascularization and less risk of repeat revascularization. ${ }^{18,22}$ Cardiac death, myocardial infarction, or angina requiring revascularization occur less frequently after CABG than after PCI in patients with DM and multivessel coronary artery disease. ${ }^{12,23-25}$ The main difference between the 2 treatments is that grafts are placed distally on the coronary arteries, whereas PCI attacks the proximal lesion. $\mathrm{CABG}$ bypasses a large amount of plaque burden in the coronary arteries and inherently prevents rein- tervention caused by progression of disease proximal to the site of the coronary anastomoses, whereas PCI does not preclude progression of lesions close to a stent. This might be of major importance in patients with DM and an aggressive generalized coronary atherosclerosis. Surgical revascularization is an effective treatment for patients with DM whose coronary artery lesions do not qualify for endovascular revascularization. $^{26}$ The advantages seen with CABG over those seen with balloon-only PCI in early trials might not be applicable in the era of drug-eluting stents, glycoprotein IIb/IIIa inhibitors, and the latest medical therapies. ${ }^{27} \mathrm{PCI}$

TABLE 3. Early and late mortality in survivors at 30 days until 5 years after coronary artery bypass grafting in patients with and without type 2 diabetes: Mortality during 1 time period compared with operations performed during 1970-1989

\begin{tabular}{|c|c|c|c|c|c|c|c|}
\hline \multirow[b]{2}{*}{ Time period } & \multicolumn{3}{|c|}{ Deaths } & \multicolumn{2}{|c|}{ Age adjusted } & \multicolumn{2}{|c|}{ Multivariable* } \\
\hline & No. & $\mathbf{n}$ & $\%$ & OR & $95 \% \mathrm{CI}$ & OR & $95 \% \mathrm{CI}$ \\
\hline \multicolumn{8}{|l|}{ Early deaths } \\
\hline \multicolumn{8}{|l|}{ Diabetes } \\
\hline 1970-1989 & 319 & 11 & 3.5 & 1 & & 1 & \\
\hline 1990-1999 & 989 & 35 & 3.5 & 0.6 & $0.3-1.2$ & 0.4 & $0.2-1.0$ \\
\hline 2000-2003 & 584 & 18 & 3.1 & 0.4 & $0.2-1.0$ & 0.3 & $0.1-0.9$ \\
\hline \multicolumn{8}{|l|}{ No diabetes } \\
\hline 1970-1989 & 3488 & 72 & 2.1 & 1 & & 1 & \\
\hline 1990-1999 & 5166 & 79 & 1.5 & 0.4 & $0.3-0.6$ & 0.3 & $0.2-0.5$ \\
\hline \multirow[t]{2}{*}{$2000-2003$} & 1869 & 36 & 1.9 & 0.5 & $0.3-0.8$ & 0.4 & $0.2-0.7$ \\
\hline & & & & HR & $95 \% \mathrm{CI}$ & HR & $95 \%$ CI \\
\hline \multicolumn{8}{|l|}{ Late deaths } \\
\hline \multicolumn{8}{|l|}{ Diabetes } \\
\hline 1970-1989 & 308 & 59 & 19.2 & 1 & & 1 & \\
\hline 1990-1999 & 954 & 131 & 13.7 & 0.5 & $0.4-0.7$ & 0.6 & $0.5-1.0$ \\
\hline 2000-2003 & 566 & 77 & 13.6 & 0.5 & $0.3-0.7$ & 0.6 & $0.4-1.0$ \\
\hline \multicolumn{8}{|l|}{ No diabetes } \\
\hline 1970-1989 & 3416 & 293 & 8.6 & 1 & & 1 & \\
\hline 1990-1999 & 5087 & 444 & 8.7 & 0.7 & $0.6-0.8$ & 0.7 & $0.6-0.9$ \\
\hline $2000-2003$ & 1833 & 122 & 6.6 & 0.5 & $0.4-0.6$ & 0.6 & $0.5-0.8$ \\
\hline
\end{tabular}

$O R$, Odds ratio; $95 \% C I, 95 \%$ confidence interval; $H R$, hazard ratio. *Adjusted for age, unstable angina pectoris, left ventricular function, creatinine clearance, history of myocardial infarction, use of an internal thoracic artery graft, length, and weight. 
TABLE 4. Mortality at 5 years after CABG in patients with type 2 diabetes in relation to type of treatment: Time period of surgical intervention compared with operations performed during 1970-1989

\begin{tabular}{|c|c|c|c|c|c|c|c|c|c|}
\hline \multirow[b]{2}{*}{ Time period } & \multicolumn{3}{|c|}{ Deaths } & \multicolumn{2}{|c|}{ Crude } & \multicolumn{2}{|c|}{ Age adjusted } & \multicolumn{2}{|c|}{ Multivariable* } \\
\hline & No. & $\mathbf{n}$ & $\%$ & HR & $95 \% \mathrm{CI}$ & HR & $95 \%$ CI & HR & $95 \%$ CI \\
\hline Insulin & 722 & 134 & 18.6 & & & & & & \\
\hline 1970-1989 & 69 & 23 & 33.3 & 1 & & 1 & & 1 & \\
\hline 1990-1999 & 373 & 66 & 17.7 & 0.5 & $0.3-0.8$ & 0.3 & $0.2-0.6$ & 0.5 & $0.3-0.9$ \\
\hline 2000-2003* & 280 & 45 & 16.1 & 0.4 & $0.3-0.7$ & 0.3 & $0.2-0.5$ & 0.4 & $0.2-0.7$ \\
\hline Oral drugs & 992 & 143 & 14.3 & & & & & & \\
\hline 1970-1989 & 151 & 30 & 19.9 & 1 & & 1 & & 1 & \\
\hline 1990-1999 & 500 & 65 & 13.0 & 0.6 & $0.4-1.0$ & 0.4 & $0.3-0.7$ & 0.5 & $0.3-0.9$ \\
\hline 2000-2003* & 341 & 47 & 13.8 & 0.7 & $0.4-1.1$ & 0.4 & $0.3-0.7$ & 0.6 & $0.3-1.0$ \\
\hline Diet only & 273 & 24 & 8.8 & & & & & & \\
\hline 1970-1989 & 75 & 3 & 4.0 & 1 & & 1 & & 1 & \\
\hline 1990-1999 & 136 & 14 & 10.3 & 2.6 & $0.8-9.2$ & 1.8 & $0.5-6.7$ & 3.0 & $0.6-15.7$ \\
\hline $2000-2003$ & 62 & 7 & 11.3 & 2.9 & $0.7-11.1$ & 1.6 & $0.4-7.0$ & 4.1 & $0.6-27.1$ \\
\hline
\end{tabular}

$H R$, Hazard ratio; $95 \% C I, 95 \%$ confidence interval. *Adjusted for age, unstable angina pectoris, left ventricular function, creatinine clearance, history of myocardial infarction, use of an internal thoracic artery graft, length, and weight.

might be a treatment of choice in patients with DM in case of discrete lesions in large vessels and severe comorbidities and if the internal thoracic artery cannot be used. Furthermore, PCI might provide effective and safe treatment in case of recurrent symptoms after CABG and could thus have contributed to improved survival in patients undergoing operations more recently. The number of patients with DM undergoing revascularization is expected to increase because the prevalence of DM is increasing globally with a high incidence of coronary artery disease. ${ }^{28}$

Our observational study includes all 12,415 first-time isolated $\mathrm{CABG}$ procedures performed at one institution over more than 3 decades. During this period, there was a considerable increase in type $2 \mathrm{DM}$, patient age, and cardiovascular risk factors and also changes in treatments. There were no operations for unstable angina before 1980. Widespread statin treatment of patients with dyslipidemia was introduced during the last decade. Overall early and 5-year multivariable adjusted mortality were about 2-fold higher in patients with DM than in those without DM and possibly somewhat lower in patients undergoing operations more recently. During 2000-2003, early and 5-year multivariable adjusted mortality were substantially reduced compared with those seen after operations performed during 1970-1989, irrespective of DM status. A significant reduction in early mortality after adjustment for confounders was a result of improvements of perioperative management in patients undergoing cardiac surgery, such as technical development of pumps and oxygenators, shorter operative times, less cooling, refined careful surgical technique and handling of grafts, methods of myocardial protection, anesthesiologic and intensive care monitoring, and practices to deal with heart, pulmonary, and renal failure in addition to the understanding and introduction of effective antithrombotic regimens. Furnary and associates ${ }^{9}$ documented that use of insulin infusion reduced hospital mortality after CABG and also that mortality in patients with DM, but not in those without DM, decreased substantially during 1987-2001.

Early mortality is influenced by factors such as operative technique and events occurring during the early recovery period, whereas late mortality should be more influenced by the patient's cardiovascular risk factors, the extent of coronary artery disease, and the degree of left ventricular impairment and patency of inserted grafts. Survival after CABG in patients with diabetes is greatly affected by associated comorbidities of peripheral vascular disease and renal failure. ${ }^{29}$ Diabetic patients treated with an early invasive strategy for unstable angina and non-ST-segment elevation myocardial infarction have a higher in-hospital and longterm mortality that is largely explained by their less favorable baseline characteristics, including more advanced coronary artery disease. ${ }^{20}$ Observed differences in survival between CABG-treated patients with and without diabetes might be largely a result of differential risk of mortality of noncardiac causes. ${ }^{2}$ Patients with insulin-dependent type 2 DM who undergo CABG have a high rate of major complications and an extremely unfavorable short- and long-term prognosis. ${ }^{8,13,17}$

The strength of the study was complete follow-up with a unique personal number linked to national registers, allowing every patient to be traced. Limitations were incomplete data on the diagnosis of DM after hospital discharge. The information on DM reflected the situation at the time of the operation. It goes without saying that during the years after the operation, DM was diagnosed in many patients who were originally not classified as having DM. ${ }^{30}$ Assumed inferior results in these patients might tend to dilute the true differences in observed long-term mortality between patients with and without DM. During the last decade, information has evolved that many patients not having a diagnosis of DM on admission have dysglycemia and a prediabetic state with an impaired fasting glucose level, high level after oral 
glucose tolerance test, or both. The important implication is that many patients listed as nondiabetic have disturbed glucose homeostasis and an increased risk after CABG ${ }^{31}$ Perioperative hyperglycemia is associated with longer postoperative care and increased hospitalization costs. ${ }^{32}$ Only a few potential confounders were consistently available in the entire database and changed the multivariable adjusted point estimate by at least $10 \%$. Patients in whom medical treatment with $\beta$-blockers and statins was started after treatment for unstable coronary syndrome were classified as having hypertension and hyperlipidemia, respectively, although we did not have more detailed information about blood pressures and lipid levels. We did not have valid information on smoking habits. Diabetes is associated with dyslipidemia, in particular increased triglyceride levels and low HDL cholesterol levels, as well as hypertension. Failure to fully adjust for these factors in analyses of mortality most likely resulted in residual confounding in estimates of ORs and HRs, reflecting the increased risk associated with diabetes. The net effect of residual confounding from major cardiovascular risk factors might have been an overestimate of the risk associated with diabetes.

An improved prognosis of survival after CABG over time in patients with DM was anticipated because continuous dramatic advances in the medical treatment of patients with ischemic cardiovascular disease and DM have occurred. As a consequence of guidelines, there is an increased awareness to treat modifiable risk factors and comorbidities. Patients are encouraged to reduce cardiovascular risk by means of cessation of smoking, dietary modifications, and physical exercise to treat obesity and control hyperlipidemia, hypertension, and renal failure. Intensive glucose and tight blood pressure control in patients will reduce the risk of diabetesrelated complications. ${ }^{33}$ ACE inhibitors reduce the risk of cardiovascular complications in patients with DM, regardless of the antihypertensive effect. ${ }^{34}$ Likewise, statins reduce the cardiovascular risk in patients with DM irrespective of the cholesterol-lowering effect. ${ }^{35}$ Use of these 2 drugs increased with time in our patients. In the United Kingdom Prospective Diabetes Study, use of metformin reduced the risk of myocardial infarction. ${ }^{36}$ We have documented an increased use of medication in our patients, but unfortunately, secondary prevention, such as uses of platelet inhibitors, statins, and ACE inhibitors and strict glycemic control, is sometimes poorly applied. ${ }^{37}$

In conclusion, multivariable adjusted early mortality and late mortality until 5 years after CABG were about 2 -fold greater in those with than in those without DM. The adjusted risks of early and late death during 2000-2003 compared with that during 1970-1989 were exceptionally reduced both in those with and without DM. Despite medical advances, late mortality after CABG in patients with DM undergoing operations recently remained increased.
We are grateful to Christian Unge, Henrik Overödder, Björn Törnkvist, Anders Giesecke, Anna Olofsson, Susanne Hylander, and Emelie Ivert for collecting information from the medical records.

\section{References}

1. Carson JL, Scholz PM, Chen AY, Peterson ED, Gold J, Schneider SH. Diabetes mellitus increases short-term mortality and morbidity in patients undergoing coronary artery bypass graft surgery. J Am Coll Cardiol. 2002;40:418-23.

2. Schwartz L, Kip KE, Frye RL, Alderman EL, Schaff HV, Detre KM. Coronary bypass graft patency in patients with diabetes in the Bypass Angioplasty Revascularization Investigation (BARI). Circulation. 2002;106:2652-8.

3. Dortimer AC, Shenoy PN, Shiroff RA, Leaman DM, Babb JD, Liedtke AJ, et al. Diffuse coronary artery disease in diabetic patients: fact or fiction? Circulation. 1978;57:133-6.

4. Ledru F, Ducimetiere P, Battaglia S, Courbon D, Beverelli F, Guize L, et al. New diagnostic criteria for diabetes and coronary artery disease: insights from an angiographic study. J Am Coll Cardiol. 2001;37:1543-50.

5. Thourani VH, Weintraub WS, Stein B, Gebhart SS, Craver JM, Jones EL, et al. Influence of diabetes mellitus on early and late outcome after coronary artery bypass grafting. Ann Thorac Surg. 1999;67:1045-52.

6. Calafiore AM, Di Mauro M, Di Giammarco G, Contini M, Vitolla G, Iaco AL, et al. Effect of diabetes on early and late survival after isolated first coronary bypass surgery in multivessel disease. J Thorac Cardiovasc Surg. 2003;125: 144-54.

7. Woods SE, Smith JM, Sohail S, Sarah A, Engle A. The influence of type 2 diabetes mellitus in patients undergoing coronary artery bypass graft surgery: an 8-year prospective cohort study. Chest. 2004;126:1789-95.

8. Alserius T, Hammar N, Nordqvist T, Ivert T. Risk of death or acute myocardial infarction 10 years after coronary artery bypass surgery in relation to type of diabetes. Am Heart J. 2006;152:599-605.

9. Furnary AP, Gao G, Grunkemeier GL, Wu Y, Zerr KJ, Bookin SO, et al. Continuous insulin infusion reduces mortality in patients with diabetes undergoing coronary artery bypass grafting. J Thorac Cardiovasc Surg. 2003;125: $1007-21$.

10. Rajakaruna C, Rogers CA, Suranimala C, Angelini GD, Ascione R. The effect of diabetes mellitus on patients undergoing coronary surgery: a risk-adjusted analysis. J Thorac Cardiovasc Surg. 2006;132:802-10.

11. Hakala T, Pitkanen O, Halonen P, Mustonen J, Turpeinen A, Hippelainen M. Early and late outcome after coronary artery bypass surgery in diabetic patients. Scand Cardiovasc J. 2005;39:177-81.

12. Hueb W, Gersh BJ, Costa F, Lopes N, Soares PR, Dutra P, et al. Impact of diabetes on five-year outcomes of patients with multivessel coronary artery disease. Ann Thorac Surg. 2007;83:93-9.

13. Kubal C, Srinivasan AK, Grayson AD, Fabri BM, Chalmers JA. Effect of risk-adjusted diabetes on mortality and morbidity after coronary artery bypass surgery. Ann Thorac Surg. 2005;79:1570-6.

14. Szabo Z, Hakanson E, Svedjeholm R. Early postoperative outcome and mediumterm survival in 540 diabetic and 2239 nondiabetic patients undergoing coronary artery bypass grafting. Ann Thorac Surg. 2002;74:712-9.

15. Toumpoulis IK, Anagnostopoulos CE, Balaram SK, Rokkas CK, Swistel DG, Ashton RC Jr, et al. Assessment of independent predictors for long-term mortality between women and men after coronary artery bypass grafting: are women different from men? J Thorac Cardiovasc Surg. 2006;131:343-51.

16. Mohammadi S, Dagenais F, Mathieu P, Kingma JG, Doyle D, Lopez S, et al Long-term impact of diabetes and its comorbidities in patients undergoing isolated primary coronary artery bypass graft surgery. Circulation. 2007;116:I220-5

17. Luciani N, Nasso G, Gaudino M, Abbate A, Glieca F, Alessandrini F, et al. Coronary artery bypass grafting in type II diabetic patients: a comparison between insulin-dependent and non-insulin-dependent patients at short- and mid-term follow-up. Ann Thorac Surg. 2003;76:1149-54.

18. Daemen J, Serruys PW. Optimal revascularization strategies for multivessel coronary artery disease. Curr Opin Cardiol. 2006;21:595-601.

19. Cockroft W, Gault MH. Prediction of creatinine clearance from serum creatinine Nephron. 1976;16:31-41.

20. Muller C, Neumann FJ, Ferenc M, Perruchoud AP, Buttner HJ. Impact of diabetes mellitus on long-term outcome after unstable angina and non-ST-segment elevation myocardial infarction treated with a very early invasive strategy. Diabetologia. 2004;47:1188-95. 
21. Echahidi N, Pibarot P, Despres JP, Daigle JM, Mohty D, Voisine P, et al. Metabolic syndrome increases operative mortality in patients undergoing coronary artery bypass grafting surgery. J Am Coll Cardiol. 2007;50:843-51.

22. Smith SC Jr, Dove JT, Jacobs AK, Kennedy JW, Kereiakes D, Kern MJ, et al. ACC/AHA guidelines for percutaneous coronary intervention (revision of the 1993 PTCA guidelines)-executive summary: a report of the American College of Cardiology/American Heart Association task force on practice guidelines (Committee to revise the 1993 guidelines for percutaneous transluminal coronary angioplasty) endorsed by the Society for Cardiac Angiography and Interventions. Circulation. 2001;103:3019-41.

23. Pell JP, Pell AC, Jeffrey RR, Jennings K, Oldroyd K, Eteiba H, et al. Comparison of survival following coronary artery bypass grafting vs. percutaneous coronary intervention in diabetic and non-diabetic patients: retrospective cohort study of 6320 procedures. Diabet Med. 2004;21:790-2.

24. Abizaid A, Costa MA, Centemero M, Abizaid AS, Legrand VM, Limet RV, et al. Clinical and economic impact of diabetes mellitus on percutaneous and surgical treatment of multivessel coronary disease patients: insights from the Arterial Revascularization Therapy Study (ARTS) trial. Circulation. 2001;104:533-8.

25. Niles NW, McGrath PD, Malenka D, Quinton H, Wennberg D, Shubrooks SJ, et al. Survival of patients with diabetes and multivessel coronary artery disease after surgical or percutaneous coronary revascularization: results of a large regional prospective study. Northern New England Cardiovascular Disease Study Group. J Am Coll Cardiol. 2001;37:1008-15.

26. Gandjbakhch I, Leprince P, D'Alessandro C, Ouattara A, Bonnet N, Varvous S, et al. [Coronary artery bypass graft surgery in patients with diabetes]. Bull Acad Natl Med. 2005;189:257-67.

27. Flaherty JD, Davidson CJ. Diabetes and coronary revascularization. JAMA. 2005; 293:1501-8

28. Amos AF, McCarty DJ, Zimmet P. The rising global burden of diabetes and its complications: estimates and projections to the year 2010. Diabet Med. 1997; 14(suppl 5):S1-85.
29. Leavitt BJ, Sheppard L, Maloney C, Clough RA, Braxton JH, Charlesworth DC, et al. Effect of diabetes and associated conditions on long-term survival after coronary artery bypass graft surgery. Circulation. 2004;110:II41-4.

30. Anderson RE, Brismar K, Ivert T. Only a minority of patients referred for elective coronary artery bypass surgery have risk factors diagnosed and treated according to established guidelines. Diab Vasc Dis Res. 2007;4:112-6.

31. Anderson RE, Klerdal K, Ivert T, Hammar N, Barr G, Owall A. Are even impaired fasting blood glucose levels preoperatively associated with increased mortality after CABG surgery? Eur Heart J. 2005;26:1513-8.

32. Estrada CA, Young JA, Nifong LW, Chitwood WR Jr. Outcomes and perioperative hyperglycemia in patients with or without diabetes mellitus undergoing coronary artery bypass grafting. Ann Thorac Surg. 2003;75: 1392-9.

33. Stratton IM, Cull CA, Adler AI, Matthews DR, Neil HA, Holman RR. Additive effects of glycaemia and blood pressure exposure on risk of complications in type 2 diabetes: a prospective observational study (UKPDS 75). Diabetologia. 2006;49:1761-9.

34. Effects of ramipril on cardiovascular and microvascular outcomes in people with diabetes mellitus: results of the HOPE study and MICRO-HOPE substudy. Heart Outcomes Prevention Evaluation Study Investigators. Lancet. 2000;355: 253-9.

35. Collins R, Armitage J, Parish S, Sleigh P, Peto R. MRC/BHF Heart Protection Study of cholesterol-lowering with simvastatin in 5963 people with diabetes: a randomised placebo-controlled trial. Lancet. 2003;361:2005-16.

36. Effect of intensive blood-glucose control with metformin on complications in overweight patients with type 2 diabetes (UKPDS 34). UK Prospective Diabetes Study (UKPDS) Group. Lancet. 1998;352:854-65.

37. Belcher PR, Gaw A, Cooper M, Brown M, Wheatley DJ, Lindsay GM. Are we negating the benefits of CABG by forgetting secondary prevention? J Hum Hypertens. 2002;16:691-7. 